\title{
Considerações sobre o abuso sexual incestuoso: efeitos e possibilidades de intervenção
}

\author{
Considerations on incestuous sexual abuse: \\ effects and possibilities of intervention
}

\author{
Carla Júlia Segre Faiman ${ }^{(1)}$
}

\begin{abstract}
Faiman CJS. Considerações sobre o abuso sexual incestuoso: efeitos e possibilidades de intervenção. Saúde, Ética \& Justiça, São Paulo. 2003;8(1/2):24-34.

RESUMO: A interdição ao incesto é um elemento fundamental no desenvolvimento do ser humano, tanto no nível individual, no familiar, como no que se refere ao aspecto social. Ela postula limites, define as gerações e introduz uma possibilidade de organização social e psicológica. Os pais exercem funções específicas no desenvolvimento da criança, como o fato de serem os protagonistas naturais das primeiras fantasias sexuais, que configuram o Complexo de Édipo. O incesto corresponde à concretização de impulsos proibidos, que deveriam permanecer impedidos de realização, relacionados ao Complexo de Édipo, o que agrava a violência psicológica desse tipo de abuso sexual, conferindo-lhe especial potencial traumático. No incesto entre pai e filha, tema deste trabalho, as conseqüências emocionais variam bastante e dependem de diversos fatores. No entanto, pode ser estabelecida uma relação entre uma maior dificuldade de integração de conteúdos psíquicos e a experiência de incesto. $\mathrm{O}$ atendimento às situações de incesto deve incluir a intervenção da Justiça e da saúde mental.
\end{abstract}

DESCRITORES: Incesto. Complexo de Édipo. Saúde Mental. Violência doméstica.

A partir da análise das fantasias inconscientes de suas pacientes e de sua própria auto-análise, Freud $^{5}$, logo nos primeiros anos da psicanálise, observou a presença e a universalidade do que veio a chamar de Complexo de Édipo, isto é, ele verificou que sentimentos de enamoramento relacionados a um dos genitores e impulsos hostis, derivados do ciúme, direcionados ao outro genitor são presentes em todas as pessoas e fazem parte do desenvolvimento psicológico normal, embora geralmente não se tenha consciência disto.

O Complexo de Édipo, que pode ser definido como sendo o complexo de idéias e sentimentos relacionados aos desejos incestuosos, suas proibições e seus desdobramentos, ocupa um lugar central na teoria psicanalítica. Em psicanálise, muito

\footnotetext{
(1) Psicóloga do Depto. de Medicina Legal, Ética Médica, Medicina Social e do Trabalho da Faculdade de Medicina da Universidade de São Paulo, Mestre em Psicologia pelo Instituto de Psicologia da USP.

Endereço para correspondência: Rua Teodoro Sampaio, 115 - São Paulo, SP, CEP: 05405-000, e-mail: cfaiman@uol.com.br
} 
da constituição psíquica pode ser definido tomandose como referência a forma como este complexo se estrutura no indivíduo. Isto significa que a interdição à realização dos impulsos incestuosos tem uma importância central no desenvolvimento psicológico, sendo considerada como o paradigma da possibilidade de reconhecimento, pelo sujeito, de que existem limites para a realização de seus desejos, para sua conduta e que balizam seu reconhecimento de si. Alguns limites se concretizam na elaboração de leis, que têm a função de possibilitar e reger o convívio humano e às quais todos devem sujeitar-se em uma comunidade. A presença de conflitos e de desejos ou impulsos antagônicos à manutenção do grupo é inerente ao convívio, desta forma o estabelecimento de regras básicas que possam reger as interações é uma necessidade, sendo assim um pressuposto para a civilização.

A proibição do incesto tem o aspecto de uma lei que estabelece uma ordem cujas repercussões são muito amplas e podem ser verificadas em diferentes níveis, como o do desenvolvimento psicológico individual, o familiar, pela definição das gerações e das funções de cada pessoa no núcleo da família, e no que se refere à interação na comunidade, uma vez que os parceiros para os filhos que crescem devem provir de famílias diferentes. Sobre a mesma questão, a partir de outro ângulo, observamos que a experiência da concretização do incesto denuncia uma falha na organização das funções na família e na sua dinâmica psicológica, e tem importantes repercussões na constituição do mundo mental das pessoas que, direta ou indiretamente, são envolvidas, caracterizando uma situação de abuso.

A interdição do incesto pode ser entendida como o paradigma de limite e de possibilidade de organização. Com a delimitação das gerações, ela imprime uma ordem e, impedindo a satisfação direta de desejos, ela possibilita que se interponha algo entre um impulso e sua satisfação, abrindo espaço para o desenvolvimento de um aparelho mental que opere com representações. A necessidade de buscar outras vias de gratificação e de alívio das frustrações demanda e impele ao desenvolvimento de capacidades relacionadas a atividade de pensamento.

Os pais exercem funções específicas no desenvolvimento da criança, como o fato de serem os protagonistas naturais das primeiras fantasias sexuais, que configuram o Complexo de Édipo. Para $\mathrm{Freud}^{7}$, é da elaboração deste Complexo, da possibilidade de se renunciar à busca da satisfação direta dos impulsos incestuosos, que se forma o superego (instância do psiquismo responsável pela "consciência moral") e se desenvolvem as condições básicas para a civilização. O fato de o relacionamento sexual incestuoso coincidir com a realização de fantasias inconscientes relativas ao Complexo de Édipo é um fator de amplificação de sua violência pela complexidade de suas repercussões no âmbito psicológico.

Há famílias nas quais a interdição ao incesto falha. São as famílias nas quais ocorrem relacionamentos sexuais incestuosos. Se a interdição do incesto pode ser entendida como a condição de possibilidade para a estruturação psicológica e social, poderia-se concluir, de forma simplista, que nestas famílias não haveria qualquer possibilidade de estruturação ou desenvolvimento mental. No entanto, uma aproximação através da clínica e da literatura relativa ao tema mostra um campo bem diferente, bem mais complexo.

A prática de atendimento a famílias com ocorrência de incesto mostra uma enorme variabilidade de formas de organização psicológica nas pessoas que têm em comum a experiência do relacionamento incestuoso, descartando qualquer articulação simplista que coloque em relação direta a vivência incestuosa concreta e a impossibilidade de elaboração do complexo de Édipo, com seus desdobramentos, como a formação do superego. Não é possível, nesse tipo de estudo, estabelecer relações de causa e efeito entre características psicológicas que possam ser observadas e a experiência de incesto, isto é, qualificar determinada característica como causa ou efeito do incesto, no entanto é de interesse estudar a dinâmica presente nesta relação.

A experiência pessoal, seu significado e seus desdobramentos são diferentes para cada pessoa que vive a situação da consumação do incesto. $A$ organização psíquica, que está em constante desenvolvimento, de forma mais acentuada em se tratando de crianças, é um fator determinante no modo de inserção da criança ou adolescente na situação do abuso sexual incestuoso e na maneira como a experiência é vivida e registrada. Mesmo a memória, os sentimentos e os efeitos ligados a esta experiência são passíveis de adquirir significados 
pessoais diversos em diferentes momentos, devido ao próprio desenvolvimento ou por associação com novos dados. Em função destas mudanças na conotação pessoal de um evento, um fato inicialmente anódino pode receber uma nova configuração a que corresponde uma grande intensidade psíquica, originando um trauma. Por outro lado, esta mesma possibilidade de mudança, quando se dá no sentido favorável a uma maior integração, corresponde ao trabalho de elaboração psíquica.

O sentimento de que se trata de uma situação proibida pode estar presente ou não, dependendo de diversos fatores; e, caso não esteja, no momento em que esta percepção se instaura, a configuração psíquica da experiência altera-se, adquirindo seu caráter traumático, mesmo que se trate de algo ocorrido no passado.

\section{Para a psicanálise trauma é o}

acontecimento da vida do indivíduo que se define pela sua intensidade, pela incapacidade em que se acha o indivíduo de lhe responder de forma adequada, pelo transtorno e pelos efeitos patogênicos duradouros que provoca na organização psíquica. Em termos econômicos, o traumatismo caracteriza-se pelo afluxo de excitações que é excessivo, relativamente à tolerância do indivíduo e à sua capacidade de dominar e de elaborar psiquicamente estas excitações (p. 678) ${ }^{12}$.

Desta forma, o trauma corresponde ao material psíquico referente a uma experiência vivida concretamente ou em fantasia, cuja assimilação e elaboração não se fizeram possíveis. Do ponto de vista da economia libidinal (isto é, da distribuição de "energia psíquica") esta impossibilidade deve-se à dimensão do afluxo de excitação despertado, que ultrapassa a capacidade de elaboração do indivíduo. Neste sentido, pode-se dizer que o abuso sexual incestuoso, conforme atesta a clínica, é uma ocorrência com grande potencial traumático. Sua dimensão é bastante complexa, nela estão implicadas a sexualidade da criança, sua fantasia, seus referenciais simbólicos, o que vai além das explicações a respeito do aspecto econômico do aparelho psíquico.

Para abordar a questão e realizar algumas considerações a respeito da participação de crianças no contexto de incesto, recorreremos à clínica e à teoria psicanalítica. Freud ${ }^{6}$ afirmou que a sexualidade infantil é "perversa e polimorfa", o que implica em dizer, em primeiro lugar, que a criança dispõe de sexualidade. "Perversa" aqui refere-se à sexualidade cuja satisfação não se vincula à relação genital propriamente dita, mas sim à satisfação de impulsos não integrados, derivados das pulsões parciais, ou ligados ao "prazer de órgão", ou seja, à estimulação direta de órgãos do corpo. "Polimorfa" significa de múltiplas formas, o que, em se tratando da sexualidade, equivale a dizer que, em função de sua plasticidade, a sexualidade pode ser estimulada, expressa ou satisfeita das mais variadas formas, o que lhe permite vincular-se a uma gama enorme de situações.

Desta forma, a sexualidade da criança, por suas características, pode ser facilmente estimulada e envolvida pela situação incestuosa. O prazer experimentado assim constitui-se em um elemento cujas repercussões na dinâmica do abuso sexual são muito complexas.

Se, por um lado, na situação do incesto há uma experiência de gratificação e, por outro, a noção de que trata-se de algo proibido, recriminável, o resultado é uma vivência de ambivalência que pode em alguns casos originar intensos sentimentos de culpa. É possível que isto contribua para um certo grau de identificação com o agressor ou, ainda, que favoreça uma associação entre o erotismo e situações que representem algum risco pessoal, de forma masoquista.

Quando existe no próprio ego, pelo seu desenvolvimento, uma condenação ao incesto, o prazer sexual despertado na relação incestuosa pode representar uma ameaça para o funcionamento psíquico, na medida em que as defesas psicológicas não parecem capazes de conter, isto é, reprimir o afluxo de excitação.

Se, além disto, pensarmos nestas implicações levando em conta a dimensão da fantasia, do complexo de Édipo, então há muito mais o que analisar. Bollas ${ }^{1}$ trata desta questão em seu texto "O trauma do Incesto". Segundo este autor, a experiência incestuosa tem efeito extremamente nocivo sobre a capacidade de fantasiar, associando grande ansiedade às atividades de fantasia e de pensamento. Isto porque, considerando as fantasias inconscientes de caráter incestuoso, comuns às 
meninas, o fato do pai, protagonista de fantasias sexuais, se aproximar da menina colocando-se como objeto sexual, é vivido como um desnudamento da fantasia e uma invasão do mundo mental. Assim, a menina pode experimentar uma incerteza quanto ao que seriam os limites asseguradores da fantasia, pois esta se confunde com a realidade. Como conseqüência, as atividades relacionadas à fantasia e ao pensamento podem ser prejudicadas em função da ansiedade que passam a despertar.

Nesse sentido também escreve Uchitel ${ }^{15}$. Ao discorrer sobre a violência do abuso sexual incestuoso, a autora faz referência ao conceito de Freud de sinistro, que se refere á sensação experimentada em uma situação que ao mesmo tempo que parece nova é estranhamente familiar, em outras palavras, uma experiência que torna manifesto o que deveria ficar oculto e secreto. $O$ efeito da vivência de sinistro é perturbador, o que equivale a dizer que se trata de um acréscimo de excitação para o aparelho psíquico, potencialmente traumático, algo que demanda elaboração.

Embora, evidentemente, qualquer situação de incesto entre pai e filha tenha gravidade em termos da organização psíquica, seus efeitos e os fatores determinantes para que ela ocorra variam muito. $A$ imago de pai, isto é, a representação psíquica que se tem do pai, fundamental na estruturação psicológica, não corresponde ao pai concreto, mas apoia-se em alguns aspectos deste. Da mesma forma podemos dizer que tudo o que se entende por função paterna, no que diz respeito à interdição dos impulsos, à representação da autoridade e à possibilidade do superego organizar-se, não é necessariamente desempenhado de forma exata ou exclusiva pelo pai, no entanto, é inegável sua relação com o mesmo. Deste modo, a experiência do incesto com o pai pode ter grande influência no desenvolvimento da personalidade. Sua nocividade dependerá de aspectos do relacionamento e, principalmente, da organização psicológica da menina.

Além deste prejuízo da figura do pai como um referencial para a construção de imagos ligadas à autoridade e do próprio superego, a criança está sujeita ainda a uma confusão na definição de seu papel no núcleo familiar, o que é a base da construção da identidade. Na situação de incesto pai-filha, a menina passa a desempenhar, ao mesmo tempo as funções de filha e de esposa, de irmã e de mãe de seus irmãos, o que significa uma perda, significa não estar de fato em nenhum destes lugares definidos na cultura. Para Uchitel ${ }^{15}$, a significação que o sujeito atribui à sua experiência vincula-se à atribuição de sentido que o 'social' faz da mesma. Desta forma, quando há, por parte da criança, a compreensão da ocorrência de um abuso sexual cometido por uma das figuras parentais, este sempre terá uma dimensão traumática, que pode ou não perpetuar-se como trauma dependendo da capacidade elaborativa do sujeito. Isto por que trata-se da violação de uma lei que tem como conseqüência tirar o sujeito "... de um lugar de direito (o de filha ou de criança, por exemplo), colocando-o num outro, de insegurança, de não identidade," o que produzirá no sujeito profundas desorganizações (p. 30).

Entre as meninas e adolescentes com quem tive contato no Centro de Estudos e Atendimento Relativos ao Abuso Sexual (CEARAS), havia algumas com sérias dificuldades de envolvimento emocional, que não se mostravam capazes de um contato afetivo. Parecia que a intimidade ou a afetividade delas era absolutamente inacessível, e, em seu lugar, permanecia uma personagem de uma meiguice artificial e estereotipada. Esta característica pode refletir um distúrbio de personalidade, como fica especialmente claro no caso de uma adolescente atendida no CEARAS. Entrevistar esta moça desperta sentimentos contraditórios. Enquanto ela conta uma série de atrocidades pelas quais supostamente passou, com a clara intenção de despertar compaixão, ela mesma não parece sensível ao seu relato. Ele soa falso, mesmo que eventualmente não o seja. A impressão é de que a intenção do ato de falar é despertar determinados sentimentos no interlocutor, e que para isto pode-se falar qualquer coisa. Relacionando esta questão ao abuso, o que se manifesta como uma dificuldade de acesso a afetos mais genuínos pode expressar uma clivagem psíquica eventualmente despertada na situação de abuso, operando como uma defesa contra o sofrimento vivido.

Um caso diferente, mas que também aponta para uma precária integração afetiva interna, é o de uma menina que, em entrevista individual, ao ser indagada sobre como seu pai 'era' com ela, responde que ele era muito bom. No entanto, tudo que ela segue relatando sobre seu contato com ele 
denota situações que ela reconhecia como maus tratos, e ela não estabelece qualquer relação ou contradição entre ser bom pai e as atitudes dele para com ela de seu relato.

É importante ressaltar que estas características não são constantes nos diferentes casos. Muitas meninas estavam distantes deste quadro, apresentando seu mundo mental muito melhor integrado no que se refere à afetividade; suas dificuldades podiam ser as mais diversas, mas de outra ordem.

Diversos autores apontam diferentes elementos ou aspectos do que podemos chamar de um prejuízo na capacidade de integração de conteúdos mentais que decorre da experiência de incesto, e que pode ter relação com estas observações clínicas. Coloco a seguir algumas destas formulações com o intuito de buscar uma articulação que enriqueça a compreensão da questão.

Ferenczi ${ }^{3}$, ao falar da situação de choque emocional sofrido pela criança em decorrência de um abuso sexual cometido por um adulto, coloca que a criança identifica-se com o agressor adivinhando e respondendo às suas vontades. Ela reagiria, então, conduzida por uma espécie de mimetismo, de forma autoplástica, complementando o desejo do adulto. Este seria, segundo o autor, o modo de funcionamento de um autômato, no qual operam apenas id e superego. Embora possa chamar a atenção a citação do superego como instância ativa neste tipo de situação de abuso, se considerarmos que a autoridade moral para a criança pode ser representada pelo adulto em questão, o superego da criança estará aderido e identificado com os desígnios colocados por ele.

Ferenczi $i^{3}$ acrescenta que: “... não existe choque, nem pavor, sem um anúncio de clivagem da personalidade. A personalidade regride para uma beatitude pré- traumática, procura tornar o choque inexistente..." (p. 104). Os fragmentos clivados se comportariam como personalidades distintas, que não se conhecem umas às outras. Isto é, na impossibilidade do ego integrar a experiência, ele sofre uma clivagem.

Shengold ${ }^{13}$ é um psicanalista com larga experiência no estudo dos efeitos da violência incestuosa no psiquismo das crianças. Uma de suas colocações é a respeito do que chama de "vertical splitting". O autor coloca que só é possível para a criança suportar situações de intenso desprazer mantendo a esperança de que um bom pai (ou mãe) possa vir em algum momento resgatá-la do sofrimento. Para este autor, o que mantém a criança viva é a esperança de que a experiência de dor possa ser transformada em uma situação de amor, ou seja, a manutenção de uma imagem mental de um bom pai. A outra alternativa, que seria manter uma imago parental má, corresponderia ao aniquilamento do sentimento de identidade da criança. Este autor explica que se o genitor que é evocado pela criança na busca de alívio é o mesmo que Ihe inflige maus tratos, o que é sentido como mau, deve, então, ser registrado como bom, o que se dá através de uma operação de fragmentação mental, de um "splitting". Para o autor, o que aparece às vezes como compulsão à repetição por parte da criança em relação à situação de abuso sexual, e que também manifesta-se como a mais forte resistência à terapia, é uma desesperada luta para encontrar uma manifestação de amor em cada reencontro com o pai abusador, a tentativa de que uma imago positiva do pai possa afirmar-se em ação, e manter, portanto, a esperança (p. 26).

Este "vertical splitting" não se caracteriza como um mecanismo neurótico ou da esquizofrenia, mas um processo mais destrutivo de fragmentação por meio do qual registros contraditórios do que é bom e do que é mau não podem colidir. Shengold caracteriza o resultado deste processo como lavagem cerebral ou auto hipnose. Algo que permite à pessoa sustentar duas versões contraditórias dos fatos e acreditar nas duas (p. 27). Este parece ser o caso da menina que ao mesmo tempo considera seu pai bom e avalia como maus a maioria de seus atos para com ela. Isto sem denotar qualquer conflito, ou seja, sem falar de qualquer atitude ou fato positivo em relação a ele.

A sustentação simultânea de duas atitudes contrárias mantidas distantes, sem estabelecer entre elas uma relação dialética, que é o que se verifica nestas situações, é o propósito e o resultado da clivagem do ego descrita por Freud, fenômeno mental presente nas perversões e na psicose ${ }^{12}$.

Summit ${ }^{14}$ utiliza uma terminologia diferente da de Shengold ${ }^{13}$, mas suas observações parecem ter importantes semelhanças. Summit coloca que, como a criança necessita estruturar sua realidade para proteger o pai, ela utiliza mecanismos que a 
possibilitam manter áreas (pockets) de "sobrevivência onde a bondade e a esperança encontrem um santuário" (p.185). Estes mecanismos podem incluir a criação de companheiros imaginários, o desenvolvimento de 'múltiplas personalidades', ou ainda a criação de estados alterados de consciência em que a criança dissocia-se de sua experiência corporal, como se olhasse à distância a si própria sofrendo o abuso. O autor salienta que os mesmos mecanismos que permitem a sobrevivência psíquica da criança são, na fase adulta, impedimentos para uma efetiva integração psicológica.

Freud" expõe a questão em "A divisão do ego no processo de defesa" (1940), fazendo uma apresentação de uma situação de conflito vivida por um menino para a qual a "solução" encontrada traduz-se em uma conduta em que duas tendências contraditórias expressam-se lado a lado, uma em favor do instinto, recusando um aspecto da realidade e, a outra, assumindo o conhecimento do referido aspecto da realidade. O preço deste mecanismo, afirma Freud ${ }^{8}$, é "uma fenda no ego, a qual nunca se cura, mas aumenta à medida que o tempo passa" (p.309).

Para Uchitel ${ }^{15}$, os ingredientes para o trauma são o desamparo, a excitação excessiva, a clivagem no interior do ego e a inoperância da representação da fantasia e do recalcamento para ligar o estímulo (isto é, para proceder à sua elaboração), o que faria com que se ativassem defesas mais primitivas (p.125). A autora prossegue escrevendo sobre a clivagem de forma a esclarecer a relação entre esta, que caracteriza a condição perversa, e o mecanismo subjacente ao trauma.

A reação ao trauma encontra também parentesco com a reação perversa: com a recusa e o reconhecimento. A clivagem no interior do ego, característica da condição perversa, é similar à operada contra a dor, a ansiedade e o perigo do trauma. Quando esta ameaça ataca e não é possível fazer-lhe frente com recursos simbólicos, seja por que inexistem, seja por que ante o impacto falham, as defesas que aparecem são mais drásticas. Como na perversão, o trauma não anula a percepção, mas não se inscreve simbolicamente (p. 119, 120).

A 'recusa' da inscrição simbólica de determinada percepção caracteriza o funcionamento perverso, sendo que esta percepção é mantida em algum registro mental. Duas versões contraditórias convivem lado a lado, induzindo o sujeito à conduta perversa, que representa uma tentativa de reverter a situação traumática conferindo-lhe outro desfecho, o que corresponderia a tentar negar em ato aquela percepção cuja inscrição no registro simbólico não pode ser feita. Stoller citado por Ferraz $z^{4}$ aponta nesta direção ao colocar a perversão como fruto da ansiedade, resultante de um trauma na identidade sexual do sujeito.

A partir de outro ângulo, Furniss ${ }^{10}$ estuda como a experiência de abuso sexual incestuoso envolvendo uma criança, com sua característica de segredo, pode constituir-se em algo dissociado, como uma lacuna, no desenrolar de acontecimentos corriqueiros, e a dificuldade de elaboração psíquica da experiência que, através desta dissociação confunde, parecendo uma "não realidade". Para o autor isto que seria uma anulação da experiência se dá em três níveis: 1- pelo contexto em que ocorre o abuso, que se refere a um controle sobre a realidade perceptual que objetiva negar a magnitude dos aspectos sexuais envolvidos na interação. A exigência de silêncio ou de escuridão podem ser exemplos de fatores envolvidos na criação de contextos assim; 2- pela transformação da pessoa que abusa em 'outra pessoa', que consiste em agir de um modo alterado em relação ao normal, como se fosse outra pessoa, alterando tom de voz, gestual, padrão de ação e de linguagem, aspecto que geralmente as crianças descrevem referindo alterações na expressão facial; 3- através de rituais de entrada e de saída da situação. Estes rituais têm importância central no aspecto interacional estudado. Por meio deles a pessoa que comete abuso 'transforma-se' em outra pessoa e a experiência é isolada no aspecto temporal do resto dos acontecimentos. O autor coloca que,

o espaço de tempo completo entre o exato início do ritual de entrada e o exato final do ritual de saída marca o período de tempo do abuso sexual. Depois do abuso, a pessoa que o cometeu e a criança cortam fora de sua realidade mutuamente reconhecida, o período de tempo e a experiência entre os rituais de entrada e saída, como se aquilo nunca tivesse existido. Eles se tornam as unidades de quinze minutos perdidas e dissociadas na vida da criança.

Por exemplo, um pai recebe em casa a criança que volta da escola, dizendo "oi, como foi a escola?”. Ele então pode iniciar o ritual de entrada 
e acontece o abuso sexual, terminando no ritual de saída. Ele então pode se voltar para a criança como se tivesse acabado de dizer "oi, como foi a escola?", e falar "agora vá fazer seu tema de casa", fingindo para ele próprio e para a criança que entre o primeiro "oi, como foi a escola?" e o bem posterior "agora vá fazer seu tema de casa" nenhum tempo se passou e nenhum abuso sexual ocorreu.. É como se as duas frases tivessem seguido uma a outra diretamente, sem nada entre elas... (p. 33)

Estas observações de Furniss ${ }^{10}$ dizem respeito a um padrão de comportamento presente na interação entre o adulto e a criança em alguns casos de abuso sexual incestuoso. Tratam-se de observações importantes na medida em que elucidam um tipo de situação que em alguns casos repete-se inúmeras vezes na vida de uma criança, podendo ter efeitos extremamente perturbadores para sua integridade psicológica, além do fato de enfraquecer as possibilidades de defesa da criança, uma vez que os referenciais em que ela baseia sua experiência são contraditórios.

Essa negação que encobre a realidade da experiência do abuso sexual favorece a instauração de um padrão de funcionamento psicológico no qual aspectos da realidade podem ter sua veracidade questionada. Dessa forma, aspectos contraditórios da realidade podem manter-se apartados, com vida independente no registro psíquico, ao que corresponde uma clivagem no próprio ego.

A clivagem do ego, ou colocado de forma mais genérica, o prejuízo da capacidade de integração do mesmo pode, portanto, estar relacionado à experiência de violência sexual incestuosa. Embora este traço não seja observado em uma proporção grande de casos, é presente em várias das crianças e adolescentes que passaram por esta experiência, e trata-se de uma característica muito importante, com sérias e duradouras repercussões para o funcionamento psíquico como um todo. A instauração de um padrão de funcionamento mental com características perversas colabora ainda para a repetição de situações de violência de uma geração à seguinte.

O prejuízo na integridade psíquica que pode ser associado a este tipo de experiência caracteriza-se em um distúrbio no funcionamento mental no que se refere à afetividade. A capacidade de empatia e de envolvimento são prejudicadas, bem como a atividade de fantasia e o desenvolvimento de recursos internos para fazer frente às tensões internas e externas. Desta forma, em um círculo vicioso, estabelecem-se, no desenvolvimento da personalidade, as pré-condições para a atuação violenta sobre o outro.

Alguns fatores sócio-culturais podem concorrer para a configuração de um quadro psicológico que favoreceria a ocorrência de comportamentos de abuso sexual, segundo Fuks ${ }^{9}$. Baseada em observações de autores britânicos ${ }^{11}$, a autora afirma que a associação da masculinidade a uma postura que valoriza a rivalidade e opõe-se a intimidade e a identificação da emoção como um traço feminino fazem com que o sexo se frature, traduzindo-se em atividade do pênis mais do que em encontro. $A$ conquista sexual passa a ser tomada como símbolo da potência masculina. Fuks ${ }^{9}$ conclui que há uma relação entre esta concepção de masculinidade e o abuso sexual, sendo o abuso geralmente inerente a um tipo de personalidade que rejeita a intimidade, $\mathrm{e}$ "...o sexo como triunfo transforma-se facilmente em sexo como rejeição e degradação do outro" (p. 122).

Este fator cultural apontado por Fuks ${ }^{9}$ favorece que a atitude violenta, que emerge como reação a sentimentos de angústia ou ansiedade relativos à própria identidade ameaçada, se expresse pela submissão do outro em um ato sexual violento.

Referindo-se a um distúrbio do funcionamento familiar, Racamier citado por Catoire $^{2}$, descreve algo que nomeia como clima de incestualidade, no qual ocorre a "sedução narcísica" e que tem como finalidade o exercício do domínio psíquico total sobre o outro, isto é, a anulação de qualquer traço de sua individualidade ou de sua autonomia. Sob este domínio, o outro ocupa o lugar de um prolongamento do abusador, de algo que o complementa em sua satisfação narcísica (relacionada a si próprio). Neste contexto, qualquer interesse sexual que uma filha possa apresentar pode ser sentido como uma ameaça de que ela se aproxime de outros e saia do domínio do abusador. A ocorrência do incesto é uma maneira de desviar o sexual e de fazê-lo trabalhar a serviço da "unidade narcísica". Assim, o abuso sexual é uma decorrência do abuso narcísico. Depreende-se então que a violência primeira consiste em impedir que os filhos possam constituir-se como unidades autônomas, como pessoas independentes, 
com projetos pessoais próprios.

Muitas vezes observamos em famílias incestuosas uma espécie de regime fechado a que são submetidos seus membros. Este pode expressar-se por um rígido controle dos relacionamentos extras familiares, muitas vezes proibidos. Mantendo uma coesão familiar em regime do que podemos chamar de perversão narcísica, a família muitas vezes restringe seus contatos externos, sob as mais diversas alegações. Desta forma, ocorre até de algumas crianças serem impedidas de ir à escola, e outras proibidas de qualquer vínculo com colegas.

A eventualidade de que uma filha tenha um namorado pode aparecer como uma ameaça para este tipo de funcionamento familiar. Além de este fato aproximar da família um elemento externo, o direcionamento do afeto da filha para uma pessoa alheia ao núcleo familiar rompe a homeostase da família. Observamos que às vezes, em famílias com este perfil, o abuso passa a ser expresso em ato a partir do momento em que se tem notícia de que a filha tem um primeiro namorado.

Deve ser lembrada a importância do papel da mãe na situação de incesto entre pai e filha. É comum que no atendimento de crianças e adolescentes que passaram pela experiência de incesto com seus pais (homens), seja muito mais expressivo um ódio dirigido à mãe do que ao pai, autor do abuso. Podemos entender este ódio como decorrente de um sentimento de que a proteção, atribuída à função da mãe, falha. Bollas ${ }^{1}$ coloca uma visão bastante interessante a respeito de como a mãe está implicada na situação a partir da ótica da criança. Ele afirma que, para a criança, o acesso do pai ao seu corpo se dá através da mãe. Como se a mãe o autorizasse, uma vez que para a criança é a mãe, pela sua função e proximidade, que legisla sobre o acesso à criança.

Fuks ${ }^{9}$ coloca que, em função desta raiva contra a mãe, a criança se afasta da identificação com esta. Se do ponto de vista da menina a imagem da mãe é de uma pessoa frágil, desvalorizada, este afastamento permite que a criança reaja, assumindo uma posição diferente, posição de alguém que realmente merece e deve ser cuidado. Um outro desfecho possível para a presença de maior raiva dirigida à mãe é descrito por Summit ${ }^{14}$. Para este autor, nessas situações o vínculo mãe- filha se enfraquece, fazendo com que a filha perca a confiança em si como mulher e não se sinta digna de proteção, o que a faria manter-se buscando aceitação e proteção no contato com homens abusivos.

Podemos pensar que aspectos relacionados ao que comumente é chamado de auto-estima, isto é, o valor pessoal que a criança preserva de si, que se reflete na qualidade das perspectivas que ela pode projetar para seu futuro e no quanto ela se sente digna de cuidados, são importantes fatores na determinação da possibilidade da criança romper (ou não) um relacionamento incestuoso. A dependência que mantém o vínculo incestuoso entre pai e filha alimenta-se da fragilidade da auto-imagem desta. Características do vínculo mãe /filha, como a imagem que a menina tem de sua mãe, sentimentos de rivalidade entre elas, a postura da mãe frente às solicitações - e à eventual comunicação da ocorrência de abuso - da filha e, especialmente, a imagem que a menina constrói de si, que em parte depende do contato com sua mãe, são fatores fundamentais na determinação de um maior ou menor risco de ocorrência de um abuso incestuoso. Uma vez ocorrido o abuso, sua perpetuação ou, ao contrário, a ruptura do vínculo incestuoso, também dependerá em grande medida desses fatores.

Pudemos ver como diferentes autores observam, cada um à sua maneira, aspectos característicos de relações incestuosas que podemos relacionar à aderência, ou não, da criança a este vínculo com seu pai. O longo período de extensão que, conforme se observa na clínica, é comum nas relações incestuosas demanda a compreensão destes aspectos. Questões ligadas à possibilidade de estruturação psicológica e de construção da identidade estão implicadas nestas situações.

O envolvimento da criança em situações incestuosas deve ser compreendido, não para emitirem-se julgamentos morais a este respeito, e nem com a finalidade de distribuírem-se atribuições de responsabilidade, mas para que se possa ajudá-la no seu desenvolvimento. Aliás, este mesmo intuito deve motivar o estudo da participação do pai, da mãe e eventualmente de irmãos na dinâmica familiar incestuosa.

Foram aqui levantados aspectos muito diversos relacionados à experiência de incesto. Um estudo desta natureza tem sua importância na 
construção teórica que nos auxilia a compreender estas situações. No entanto, cada caso de abuso sexual incestuoso é diferente do outro, sendo importante reforçar que o trabalho de análise com função terapêutica deve sempre partir da experiência particular, livre de posicionamentos definidos 'a priori'. Aliás, é assim que deve ocorrer em qualquer situação na qual se empreenda um trabalho de análise.

\section{O ATENDIMENTO A SITUAÇÕES DE ABUSO SEXUAL INCESTUOSO}

Pela complexidade da questão, o atendimento a situações de abuso sexual demanda diferentes abordagens, como a de saúde mental, a jurídica, e a de saúde em termos mais gerais, no que se refere ao corpo. A cada abordagem corresponde um tipo especifico de intervenção. A experiência de centros de atendimento como o CEARAS, que realiza atendimentos em saúde mental de pessoas encaminhadas pelos Fóruns de Justiça, traz à reflexão algumas questões referentes à definição das atribuições e das funções de cada instituição na atenção a situações de incesto. O ideal é que o atendimento prestado pela Justiça e o atendimento em saúde mental possam ocorrer de forma articulada, num contexto no qual estejam claramente definidos e respeitados os limites de cada uma destas abordagens.

Cabe aos profissionais ligados às instituições judiciárias buscar a realidade concreta dos fatos que balizará a tomada de decisões do juiz. Podem assim ser realizadas perícias investigando a ocorrência e as condições ligadas ao abuso. A equipe técnica das varas de infância e juventude dos Fóruns, composta de psicólogos e assistentes sociais, realiza um acompanhamento das famílias que têm processo judicial em função de denúncia de abuso sexual que envolva crianças ou adolescentes. A função deste trabalho é de fornecer elementos que ampliem a compreensão das situações em questão auxiliando o juiz na promoção de ações que visem à proteção da criança. Cabe à Instituição Judiciária determinar medidas de proteção, como, por exemplo, ordenar que pai e filha morem em locais distintos no caso de haver relacionamento incestuoso entre eles. Também é função da Justiça responsabilizar legalmente quem comete o abuso, o que se dá por meio dos processos em varas criminais.

A intervenção da Justiça, com as medidas concretas que ela impõe e o poder que ela representa, é de importância capital para a cessação de comportamentos de abuso sexual. $\mathrm{O}$ atendimento prestado em saúde mental age de forma complementar, visando o desenvolvimento dos recursos psicológicos individuais e familiares, intervindo assim nos fatores de natureza psíquica presentes na dinâmica dos relacionamentos incestuosos.

O trabalho em saúde mental pauta-se no vínculo de confiança que pode se desenvolver entre paciente e terapeuta, portanto o sigilo profissional deve ser uma garantia para o trabalho. Confiança não se confunde com cumplicidade, sendo importante que as investigações cabíveis à Justiça caminhem de forma independente e paralela à psicoterapia. Assim, o psicoterapeuta, devido à natureza de seu trabalho, não pode ter como função dar informações à Justiça, o que colocaria em xeque o atendimento que presta. No CEARAS este pensamento faz com que os atendimentos dirijam-se a famílias que têm necessariamente uma denúncia de abuso sexual incestuoso previamente realizada à Justiça. Em função desta exigência do CEARAS, a sua principal fonte de encaminhamento de pacientes são as Varas da Infância e da Juventude dos Fóruns de Justiça.

A maior parte das instituições que prestam atendimento psicológico e social a situações de abuso sexual volta-se para o atendimento das pessoas que são vistas como vítimas de violência, geralmente mulheres e crianças. Podemos citar como exemplos, em São Paulo e arredores, o Programa de Atenção às Vítimas de Abuso Sexual (PAVAS), o Centro Regional de Atenção aos Maus tratos na Infância (CRAMI), a Casa Eliane de Grammont, Centro de Referência às Vítimas de Violência (CnRVV), entre outras. Algumas destas instituições têm vinculo com abrigos que recebem mulheres e crianças em situação de risco. Cada uma a seu modo acolhe, oferece tratamento e/ou encaminhamento aos seus pacientes.

No que se refere à saúde mental, em se tratando de abuso cometido dentro da família, uma proposta de atendimento deve levar em conta a complexidade e os aspectos de ambigüidade envolvidos na dinâmica psicológica familiar 
implicados na situação de abuso. É sempre presente o risco de o profissional de saúde voltado para o atendimento de "vítimas", pela dificuldade de analisar a situação em sua complexidade, identificar-se com aspectos do sofrimento do paciente que recebe de uma forma que toda a atribuição de responsabilidade e de "maldade" seja projetada no familiar ausente, negando qualquer aspecto relacionado aos vínculos emocionais envolvidos. Quando isto ocorre, características menos superficiais do funcionamento mental escapam do seu campo de intervenção, o que resulta em ações que têm valor na urgência de algumas situações de violência, mas não têm efetividade no favorecimento do desenvolvimento de recursos psicológicos dos pacientes.
$O$ atendimento familiar, desvinculado de qualquer função pericial, abre uma possibilidade de se abordar a dinâmica dos relacionamentos no núcleo familiar em sua complexidade e ultrapassar a freqüente tendência a interpretações maniqueístas em que a identificação de cada pessoa da família permanece aderida a aspectos unicamente bons (de vítima) ou exclusivamente maus (de vilão). A disposição de incluir o agressor sexual nos atendimentos, individuais ou familiares, consiste na possibilidade de escutar o seu sofrimento psíquico, seja qual for a sua responsabilidade pelos atos denunciados, e permite uma compreensão maior e uma aproximação mais eficaz dos aspectos psíquicos envolvidos no abuso sexual incestuoso.

Faiman CJS. Considerations on incestuous sexual abuse: effects and possibilities of intervention. Saúde, Ética \& Justiça, São Paulo. 2003;8(1/2):24-34.

\begin{abstract}
The interdiction to the incest is fundamental in the human being development, at the individual and family levels, as well as in regard to the social aspect. It postulates limits, defines the generations and introduces the possibility of social and mental organization. Parents have a special role in child development. They are the main figures in the child's first sexual fantasies, which configure the Oedipus Complex. The incest action represents the factual realization of such prohibited impulses, which should be repressed. Such fact increases the violence of this kind of sexual abuse. In the incest between father and daughter the emotional consequences depend on several factors and can vary a lot. In spite of such variety of consequences it's possible to associate the occurrence of the incest to a higher difficulty in integrating mental contents by the child. The care in the incest situation must include the intervention of mental health professionals as well as the intervention of the Law.
\end{abstract}

KEY WORDS: Incest. Oedipus complex. Mental health. Domestic violence.

\title{
REFERÊNCIAS
}

1. Bollas C. O trauma do incesto. In: Forças do destino: psicanálise e idioma humano. Trad. Rosa Maria Bergallo. Rio deJaneiro: Imago; 1992.

2. Catoire G. Séduction et incestualité. J Psychanal L' Enfant. 1999;25:73-90.

3. Ferenczi S (1933). Confusão de língua entre adulto e criança. Trad. Álvaro Cabral. São Paulo: Martins Fontes; 1992. (Psicanálise IV: obras completas).

4. Ferraz FC. A erotização do ódio na perversão. In: Percurso, São Paulo. 200110 sem.;(26):121. Resenha de Stoller, R. J. Perversion: the erotic form of hatred. London: Karnak Books; 1986 [1975] .

5. Freud S (1897). Extratos de documentos dirigidos a Fliess: cartas: 69, 71, 72 e 75. In: Edição Standard
Brasileira das Obras Psicológicas Completas de Sigmund Freud. Trad. de Jayme Salomão. Rio de Janeiro: Imago; 1977. v.1.

6. Freud S (1905). Três ensaios sobre a teoria da sexualidade. In: Edição Standard Brasileira das Obras Psicológicas Completas de Sigmund Freud. Trad. de Jayme Salomão. Rio de Janeiro: Imago; 1977. v.7.

7. Freud S (1923). O ego eo id. In: Edição Standard Brasileira das Obras Psicológicas Completas de Sigmund Freud. Trad. de Jayme Salomão. Rio de Janeiro: Imago; 1977. v.19.

8. Freud S (1940). A divisão do ego no processo de defesa. In: Edição Standard Brasileira das Obras Psicológicas Completas de Sigmund Freud. Trad. de 
Jayme Salomão. Rio de Janeiro: Imago; 1977. v. 23.

9. Fuks LB. Abuso sexual de crianças na família: reflexões psicanalíticas. Percurso, São Paulo. 1998;20:1.

10. Furniss T. Abuso sexual da criança: uma abordagem multidisciplinar. Trad.: Maria Adriana Veríssimo. Porto Alegre: Artes Médicas; 1993.

11. Glaser D, Frosh $S$. Abuso sexual de niños. Buenos Aires: Paidós; 1997. p.41 apud Fuks, 1998.

12. Laplanche J, Pontalis JB. Vocabulário da psicanálise.
São Paulo: Martins Fontes; 1991.

13. Shengold L. Soul murder: the effects of childhood abuse and deprivation. New York: Yale University Press; 1989.

14. Summit RC. The child sexual abuse accommodation syndrome. Child Abuse Neglect Int J. 1983;7:177-93.

15. Uchitel M. Neurose traumática: uma revisão crítica do conceito de trauma. São Paulo: Casa do psicólogo; 2001. (Col. Clínica Psicanalítica) 